\title{
EL COS HUMÀ PER DINS
}

\section{Anna Font Sanz i Núria Casso Samsó. Mestres del CEIP "L’Arjau”. Vilanova i la Geltrú}

Després de més de 20 anys a l'ensenyament fent de mestres, intentant renovar la nostra pedagogia per apropar-la cada cop més als interessos i a les motivacions dels nostres alumnes, vàrem tenir l'oportunitat d'adquirir una nova visió de l'ensenyament de les ciències a partir del curs Intercanvi d'experiències de ciències que impartia en Jordi Martí Feixas.

Ens va ensenyar a pensar sobre quina finalitat tenia per a nosaltres ensenyar ciències. Fins aquell moment per a nosaltres l'ensenyament-aprenentatge de les ciències era una transmissió-recepció de coneixements. Ens vàrem adonar que això no tenia cap sentit per als nostres alumnes si no aconseguíem que fossin capaços de construir un pensament científic propi proper a la realitat. Havíem de partir de les seves hipòtesis, aprofitant la seva curiositat, imaginació, ganes d'explorar, manipular, experimentar i comunicar-se, per ajudar-los a evolucionar cap a models explicatius científics de la realitat.

En tot aquest procés era molt important que com a mestres sabéssim dissenyar activitats que servissin per explorar les idees dels nostres alumnes, interpretar aquestes idees $\mathrm{i}$ buscar estratègies que ajudessin al seu desenvolupament.

Vàrem decidir començar la nova experiència i com a tema ens va semblar motivador El cos humà per dins, amb la idea d'aprofundir en l'aparell digestiu amb els alumnes de $2 n$ curs de cicle inicial.

\section{Sessions de treball}

1 a sessió

Objectiu: Esbrinar què saben els nostres alumnes.

Pregunta: Què coneixeu del vostre cos per dins?

Activitat: Posats en rotllana, van mantenir una conversa molt viva sobre els òrgans del nostre cos i el seu funcionament. El que més coneixien era l'esquelet, i la discussió més important va ser sobre qui dirigia el cos: el cervell o el cor. Van arribar a la conclusió que el nostre cos funcionava com un cotxe, el motor era el cervell i el volant era el cor.

Ens vàrem adonar que els nostres alumnes sabien moltes més coses del seu cos per dins del que ens imaginàvem.

\section{2a sessió}

Objectiu: Què passa quan ens mengem una galeta?

Activitat: Donem una galeta a cada nen/a i els de- manem que se la mengin a poc a poc i pensin què passa amb aquella galeta dins el seu cos.

Anaven verbalitzant les seves sensacions i el recorregut que feia la galeta.

3a sessió

Objectiu: Saber quin coneixement té cada nen del seu cos per dins.

Activitat: Dibuixar la silueta del seu cos en un full DIN-A3 i representar-hi el recorregut de la galeta.

Al lliurar el full argumentaven el que havien dibuixat. 4a sessió

Objectiu: Posar en comú els coneixements individuals.

Activitat: Exposar els dibuixos fets i defensar-los.

Aquí van iniciar una gran discussió sobre els òrgans que hi intervenen, on estan colllocats i quina funció tenen.

$\underline{5 a}$ sessió

Objectiu: Contrastar la realitat de l'aparell digestiu amb els seus coneixements.

Pregunta: On podeu buscar informació del recorregut de la galeta des que ens la mengem fins que...?

Resposta: La seva resposta va ser: a casa, a la biblioteca, a internet, preguntar-ho a algú que ho sabés...

6a sessió

Objectiu: Parlar de les noves informacions que havien aportat.

1a activitat: Posar en comú les noves informacions.

Van parlar amb molta més precisió dels òrgans i de la seva funció.

La seva gran preocupació eren els aliments bons $i$ els dolents. Deien que els aliments dolents sortien per la caca (amb això es van posar d'acord de seguida). Els aliments bons es repartien per tot el cos per fer-lo créixer, per moure'ns, per tenir força...

També van arribar a l'acord que eren les venes les que repartien els aliments per tot el cos. Però com agafen les venes els aliments? Qui ordena que els reparteixin? I la pregunta permanent, on no es posaven d'acord: qui mana en el nostre cos?

$2 a$ activitat: Fer un mural consensuat.

Cada taula va fer un mural en un paper d'embalar. Van dibuixar la silueta d'un nen /a de mida natural i després de posar-se d'acord, varen dibuixar el recorregut de la galeta. 


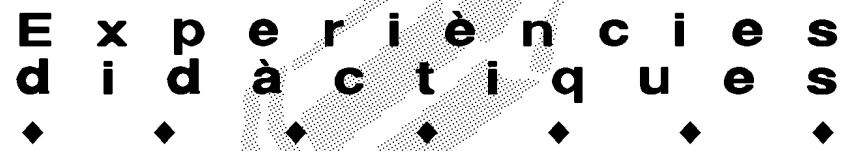

7a sessió

Objectiu: Parlar i aprendre dels murals.

Pregunta: Per què no tots els murals són iguals? Els nostres cossos són diferents?

Varen arribar a les següents conclusions:

- Tots els nostres cossos funcionen igual.

- Dins el nostre cos el cor mana a les venes que reparteixin els aliments bons, Nosaltres vàrem decidir explicar com agafaven les venes els aliments, ja que ells no ho van descobrir. Parlaven de vitamines, proteïnes, però no van esbrinar com arribaven a les venes.

- El cervell fa que els nervis diguin al cor on ha de repartir el menjar

- Tant el cervell com el cor són molt importants; si no funcionen, ens morim.

$\underline{\text { 8a sessió }}$

Objectiu: Avaluació dels seus coneixements.

Activitat: Tornar a dibuixar individualment en full DIN-A3 la silueta del seu cos i el recorregut de la galeta i com es reparteixen els aliments.

Ens vàrem adonar que en general l'evolució dels coneixements havia estat important, però cadascú segons la seva motivació, el seu interès i la seva maduració.

\section{9a sessió}

Objectiu: Fer una maqueta.

Pregunta: Què necessitarem per fer una maqueta de tot el que hem après?

Els expliquem que ens agradaria fer una maqueta de mida natural del nostre cos representant cada part i cada òrgan, igual que han fet en el paper d'embalar. Cal decidir els materials que necessitem.

Varen decidir fer servir els següents materials: un tub (esòfag); un globus gran (estómac); un globus petit (fetge); un globus allargat (pàncrees); paper de seda arrugat (cervell); cor de goma; fil elèctric vermell (venes); fil elèctric blau (nervis) tub prim de $6 \mathrm{~m}$ (intestí prim) i un tub gruixut (intestí gruixut).

\section{0a sessió}

Objectiu: Fer la maqueta.

Activitat: Vàrem posar sobre la taula els diferents materials que havien demanat, de diferents mides, colors, textures i flexibilitat.

Ells varen triar el que volien posar, representant cada òrgan i raonant cada element.

Per exemple: "El tub de l'esòfag van decidir que no havia de ser rígid perquè si no, no ens podríem doblegar i no conduiria els aliments cap a l'estómac", o "L'intestí prim havia de ser un tub prim amb petits forats perquè les venes poguessin "xuclar" els aliments".
11 sessió

Objectiu: Visualitzar i manipular un conill per dins.

Activitat: Vàrem agafar un conill mort $\mathrm{i}$ el vàrem penjar a la classe.

$\mathrm{Li}$ vàrem treure la pell $\mathrm{i}$ el vàrem obrir per fer un paral-lelisme entre el nostre cos per dins i el del conill.

Vàrem posar els diferents òrgans en safates $i$ els varen manipular.

\section{Raons per continuar treballant d'aquesta manera}

Amb la realització d'aquesta activitat ens hem adonat que els nostres alumnes saben moltes més coses del que ens imaginàvem, i que estan molt més predisposats a aprendre quan l'ensenyament es fa de la manera que hem explicat abans. Per altra part, tots els seus coneixements són vàlids i útils, ja que saben argumentar-los i defensar-los. Però cal tenir sempre present que cada nen/a evoluciona segons les seves circumstàncies. Finalment, volem dir-vos que aquesta manera de treballar fomenta la comunicació, la cohesió i el respecte de tot el grup.

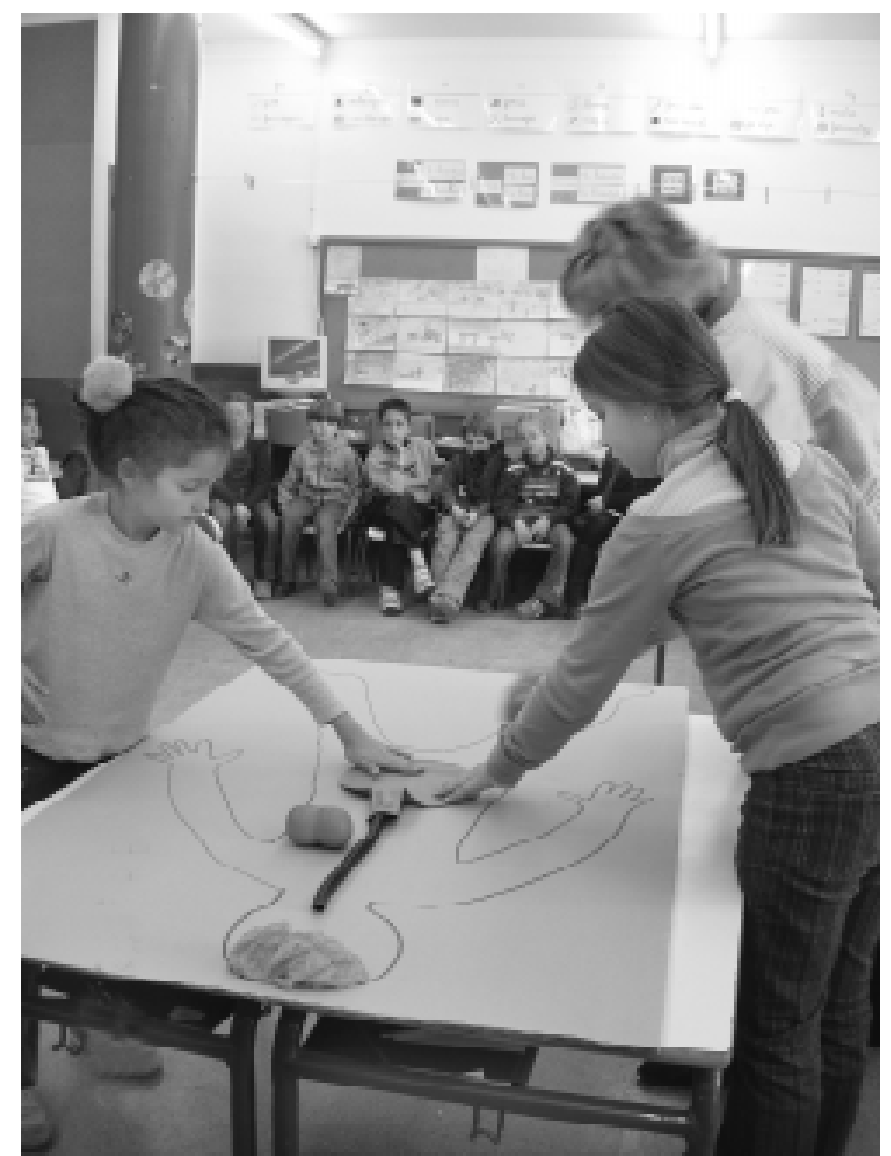

Començant la construcció de la maqueta del cos humà. 